\title{
WETLAND MAPPING IN NEW BRUNSWICK, CANADA WITH LANDSAT5-TM, ALOS-PALSAR, AND RADARSAT-2 IMAGERY
}

\author{
A. LaRocque ${ }^{1, *}$, B. Leblon ${ }^{1}$, R. Woodward ${ }^{2}$, Laura Bourgeau-Chavez ${ }^{3}$ \\ ${ }^{1}$ Faculty of Forestry and Environmental Management, University of New Brunswick, \\ Fredericton (NB), E3B 5A3, Canada - (larocque, leblon)@unb.ca \\ ${ }^{2}$ The Nature Trust of New Brunswick, Fredericton, NB, E3B 5A6, Canada - naturetrest@ntnb.org \\ ${ }_{3}^{3}$ Michigan Tech Research Institute, Ann Arbor, MI 48105, USA - lchavez@mtu.edu
}

Commission III, WG III/7

KEY WORDS: Wetland, Atlantic Canada, Landsat-TM, Radarsat-2, Alos-1 PalSAR, Random Forests

\begin{abstract}
:
Several maps of wetland areas in central New Brunswick, Canada, were produced by applying the Random Forests classifier to different combinations of optical Landsat-5 TM images, dual-polarized (HH, HV) Radarsat-2 C-band and Alos-1 PalSAR L-band Synthetic Aperture Radar (SAR) images and digital elevation data. The resulting maps were compared to 199 GPS wetland sites that were visited between 2012 and 2018 as well as to a combination of two wetland maps currently used by the Province of New Brunswick. The number of correctly identified GPS wetland sites was the highest when both the Alos-PalSAR and Radarsat-2 images are used (97.9\%). This percentage of correctly identified sites were well above the accuracy of the official New Brunswick wetland maps (44.7\%). With the best-classified image, the misidentifications were due to wetlands not being classified in the right wetland class, and just one case was a wetland site being classified in a non-wetland class. For the NB wetland map, about a quarter of the wetland validation sites were classified in a non-wetland class, and about the same number of sites were classified in the wrong wetland class.
\end{abstract}

\section{INTRODUCTION}

Wetlands are important ecosystems that perform a variety of services that are beneficial to society and the environment. They are crucial for groundwater recharge, flood control, water quality improvement, and mitigation of erosion (Li, Chen, 2005). Understanding the distribution and dynamics of wetlands is essential for understanding ecosystem diversity and function and how human practices and global changes impact it. There is increasing global importance of wetlands, as there has been an extensive wetland loss in the last half-century due to anthropogenic pressures for land-use changes and development (Henderson, Lewis, 2008). A detailed and accurate wetland inventory would be a useful tool to protect them (Reimer, 2009).

Developing a mapping method to extract information about wetland areas from satellite imagery is essential for mapping large scale regions such as the Province of New Brunswick (Canada). Satellite remote sensing has several advantages over other methods for large area mapping, such as aerial photograph interpretation and ground surveys, as they provide multitemporal data with large footprints and moderate resolution. Most satellite images are readily available from multiple dates, allowing multi-seasonal analysis, which improves mapping accuracy and is more cost-effective than other mapping methods (Li, Chen, 2005). Satellite images provide a practical approach to mapping wetlands in New Brunswick, given the remoteness of some parts of the province. Optical images like those acquired by Landsat, SPOT or Sentinel-2 satellites were already tested for mapping wetlands (e.g., Amani et al. 2017). However, accuracy was quite low. Optical imagery has the additional inconvenience of having an availability, which is limited to clear sky conditions.

By contrast, Synthetic Aperture Radar (SAR) images are of longer wavelengths (cm-scale vs. nm-scale), which penetrate clouds and, therefore, can be acquired whatever the weather conditions. SAR imagery has long been known as suitable for wetland mapping because radar waves can more easily penetrate the vegetation canopy for the detection of flooded areas and are sensitive to moisture conditions (Brisco et al., 2011; 2013b; White et al., 2014; Mahdianpari et al., 2017). Both L- and C-band images were shown to be appropriate for wetland mapping. Lband can penetrate the forest canopies and detect standing water (Henderson, Lewis, 2008). C-band data have also been useful in detecting standing water in the case of short vegetation ( $\mathrm{Li}$, Chen, 2005; Henderson, Lewis, 2008), and in some forested wetlands with low-density canopies or leaf-off conditions (Townsend, 2002). The best approach will be to combine both optical and SAR imagery. There are several studies on wetland mapping that use this approach (e.g., Li, Chen 2005; Bourgeau-Chavez et al. 2009; 2015; 2016; Corcoran et al. 2012, 2013; LaRocque et al. 2014, Amani et al. 2018; Jahncke et al. 2018; Mahdianpari et al. 2020), but the accuracy achieved by these studies was rarely above $90 \%$.

In this study, a combination of optical Landsat5-TM images with Radarsat-2 C-band and/or the Alos-PalSAR L-band SAR dualpolarized (HH, HV) images was tested for mapping wetlands in central New Brunswick, Canada. To take account of the local topography, a digital elevation model (DEM) was also used in the classification. The maps were produced using the Random Forests (RF) classifier applied to various image combinations. By contrast to the standard supervised maximum likelihood classifier (MLC), RF is a supervised non-parametric classifier that does not require normal data distribution (Breiman, 2001). Also, compared to the classical MLC, RF was showed to outperform in several land cover studies (Pal, 2005; Gislason et al., 2006; Waske, Braun, 2009; LaRocque et al., 2014). For assessing the map accuracy, the resulting maps were compared to GPS field data as well as to a combination of two wetland maps used by the Province of New Brunswick. 


\section{MATERIALS AND METHODS}

\subsection{Study area}

The Greater Fredericton area is in the heart of the Province of New Brunswick (Canada), lying between Lat $45^{\circ} 40^{\prime}$ and $46^{\circ} \mathrm{N}$ and Long $66^{\circ} 15^{\prime}$ and $66^{\circ} 50^{\prime} \mathrm{W}$ (Figure 1). This area (approximately $2,700 \mathrm{~km}^{2}$ ) is relatively easy to access and contains all the wetland classes that can be found in Eastern Canada, such as peatlands (which include bogs and fens), marshes, aquatic beds, shrub wetlands, and forested wetlands. The drainage network is dominated by the St. John River, with some major tributaries. As indicated by the 1:50,000 DEM (Figure 1), the elevation in the study area ranges from $1 \mathrm{~m}$ above mean sea level (AMSL) in the downstream portion of the St-John River to $225 \mathrm{~m}$ AMSL in the highlands of the western part of this region. The topography is rolling in most of this area, except in the lowest portion of the St. John River valley and the Grand Lake basin (east part of the study area) where the surface is mostly flat.

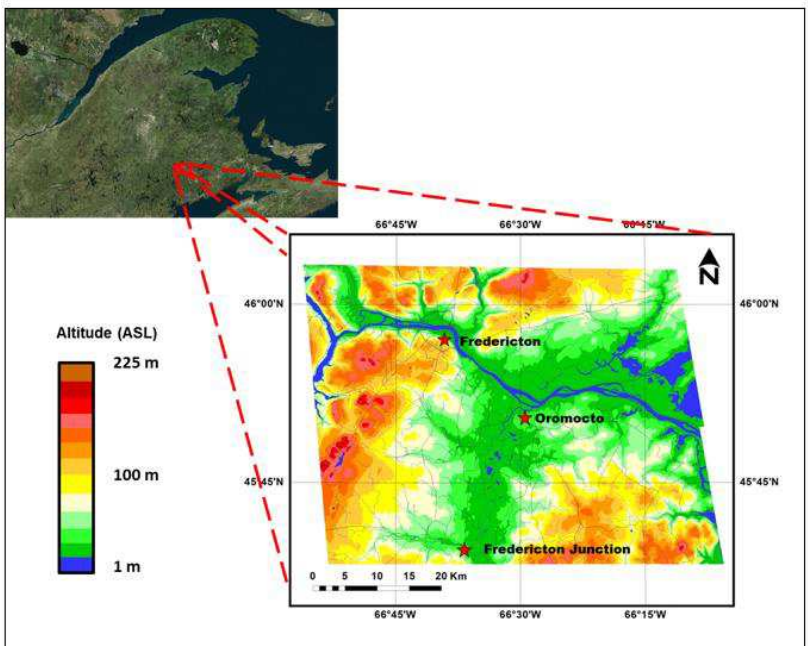

Figure 1. Location of the Greater Fredericton area in Central New Brunswick (Canada).

Sixteen land cover classes were considered in this study; namely, (1) Urban dense, (2) Urban sparse, (3) Cultivated, (4) Pasture, (5) Grass, (6) Softwood forest, (7) Hardwood forest, (8) Mixed forest, (9) Scrub Shrub, (10) Bare land, (11) Peatland, (12) Marsh, (13) Shrub wetland, (14) Forested wetland, (15) Aquatic bed, and (16) Water. The non-wetland classes are defined according to land cover classification scheme from NOAA (2017), and the wetland classes are defined following the Canadian Wetland Classification System (National Wetland Working Group, 1997) and DNR (2006).

\subsection{Data}

Three types of satellite imagery were used in the classification (Table 1): (1) Landsat-5 Thematic Mapper (TM) optical imagery (pixel size of $30 \mathrm{~m}$, and swath of $185 \mathrm{~km}$ ); (2) Alos-1-PalSAR dual-polarization ( $\mathrm{HH}$ and $\mathrm{HV}$ ) L-band (23.62 cm wavelength) SAR imagery (pixel spacing of $12.5 \mathrm{~m}$, nominal resolution of 20 $\mathrm{m}$, and swath of $70 \mathrm{~km}$ ); and (3) Radarsat-2 SGF Standard dualpolarization (HH and $\mathrm{HV}$ ) C-band (5.54 $\mathrm{cm}$ wavelength) SAR imagery (pixel spacing of $12.5 \mathrm{~m}$, nominal resolution of $25 \mathrm{~m}$, and swath of $100 \mathrm{~km}$ ). Images used in this study were acquired during high-water levels (May to early June) and low-water levels in the wetlands (Mid-August to Mid-September) (Table 1). All images were collected during ice-free and snow-free periods, and the soil was completely unfrozen.
Two georeferenced Landsat-5 TM level 1 GeoTiff images (with less than $0.1 \%$ cloud cover) were obtained from the USGS Landsat archive (glovis.usgs.gov). The six optical bands of Landsat-5 TM were used in the classification. The wavelengths of these bands are as follows: TM1 $(0.45-0.52 \mu \mathrm{m}$, blue), TM2 (0.52-0.60 $\mu \mathrm{m}$, green), TM3 (0.63-0.69 $\mu \mathrm{m}$, red), TM4 (0.76$0.90 \mu \mathrm{m}$, near-infrared), TM5 $(1.55-1.75 \mu \mathrm{m}$, short-wave infrared), and TM7 (2.08-2.35 $\mu \mathrm{m}$, short-wave infrared).

Six Alos-1 PalSAR L-band dual-polarized images were acquired during three different dates (Table 1), with an incident angle at about $38^{\circ}$, from an ascending orbit looking east. For each date of acquisition. Three Radarsat-2 dual-polarized images were also acquired (Table 1) with a Standard beam mode (S6), and an ascending (A) or descending (D) orbit. The S6 beam mode corresponds to incident angles ranging from $41^{\circ}$ to $46^{\circ}$. The images were acquired with an ascending east-looking orbit and with a descending west- looking orbit. The ascending orbit occurs during the evening hours and the descending orbit during the early morning. Both types of SAR imagery were acquired under different moisture conditions, as shown by the precipitation data recorded at the Fredericton Airport weather station (Table 1).

\begin{tabular}{|c|c|c|c|c|}
\hline Satellite & $\begin{array}{c}\text { Acquisition } \\
\text { Date }\end{array}$ & $\begin{array}{c}\text { Local } \\
\text { Time }\end{array}$ & $\begin{array}{c}\text { Precipitations } \\
{\text { [mm }]^{1}}^{{ }^{2}}\end{array}$ & $\begin{array}{c}\text { Wetland } \\
\text { Water Level }\end{array}$ \\
\hline $\begin{array}{c}\text { Landsat-5 } \\
\text { TM }\end{array}$ & $01 / 09 / 2010$ & $11 \mathrm{~h} 03$ & 0.0 & low \\
& $31 / 05 / 2011$ & $11 \mathrm{~h} 02$ & 2.6 & high \\
\hline \multirow{3}{*}{ Radarsat-2 } & $06 / 05 / 2008$ & $19 \mathrm{~h} 25$ & 2.0 & flooding \\
& $04 / 06 / 2010$ & $7 \mathrm{~h} 28$ & 62.2 & high \\
& $08 / 09 / 2010$ & $7 \mathrm{~h} 28$ & 15.6 & low \\
\hline \multirow{2}{*}{ Alos-1 } & $04 / 05 / 2008$ & $23 \mathrm{~h} 45$ & 0.6 & flooding \\
PalSAR & $10 / 05 / 2010$ & $23 \mathrm{~h} 49$ & 12.8 & high \\
& $10 / 08 / 2010$ & $23 \mathrm{~h} 48$ & 27.2 & low \\
\hline
\end{tabular}

1 Millimetres of rain equivalent recorded at the Fredericton Airport weather station during three days before image acquisition.

Table 1. List of the imagery used for this study

Ancillary data included a 1:50,000 DEM that was used to terrain correct and to georeference the SAR images and to consider the topographic effects in the image classification. This DEM was obtained from Natural Resources Canada's website (http://ftp.maps.canada.ca/pub/nrcan rncan/elevation/cdem mn ec/). Ground elevations are recorded in meter relative to Mean Sea Level (MSL), based on the North American Datum 1983 (NAD83) horizontal reference datum.

Finally, the wetland map extracted from the classified image was compared to the wetland map derived from the combination of two maps currently in use by the Province of New Brunswick: (1) the wetland map from the Department of Environment, and (2) the wetland classes in the forest map of the Department of Natural Resources. Both maps were downloaded in a shapefile format from the GeoNB website (www.snb.ca/geonb1/e/DC/catalogue-E.asp). The map produced from the combination of these two maps will be called hereafter "NB wetlands map". The image-based maps and the NB wetland map were compared to GPS that were collected during summers between 2012 and 2018. 830 field sites that were spread throughout the study area were visited (Table 2). Less than half of these sites (340) were used to delineate training areas for the image classification. The remaining sites (490) were used as validation sites to assess the mapping accuracy of each classified image and the NB wetland map. These sites were selected according to various criteria, among them a relatively large extent (at least 10 pixels or $9000 \mathrm{~m}^{2}$ ) of the related land cover class. 


\begin{tabular}{|l|c|c|c|}
\hline Land cover class & Training sites & Validation sites & Total \\
\hline Urban dense & 21 & 28 & 49 \\
Urban sparse & 20 & 31 & 51 \\
Cultivated & 22 & 27 & 49 \\
Pasture and Hay & 23 & 31 & 54 \\
Grassland & 15 & 31 & 46 \\
Softwood forest & 17 & 25 & 42 \\
Hardwood forest & 13 & 27 & 40 \\
Mixed forest & 14 & 27 & 41 \\
Scrub shrub & 25 & 35 & 60 \\
Bare land & 23 & 29 & 52 \\
Peatland & 21 & 24 & 45 \\
Marsh & 21 & 29 & 50 \\
Shrub wetland & 20 & 30 & 50 \\
Forested wetland & 37 & 59 & 96 \\
Aquatic Bed & 28 & 34 & 62 \\
Water & 20 & 23 & 43 \\
\hline Total & 340 & 490 & 830 \\
\hline
\end{tabular}

Table 2. Number of sites per land cover class used for the image classification (training sites) and the accuracy assessment of each classified image (validation sites).

Among all the visited sites, 346 sites (147 training sites and 199 validation sites) were considered as a wetland site, according to Tiner (1999)'s criteria: the water table was close to (less than 10 $\mathrm{cm}$ ) or at the surface, or we found indicator plants, soil hydromorphy, or other evidence of an area that is very often saturated with water. Most of the wetland sites were found by interpretation of aerial photographs, and some of them were previously mapped as a wetland on the NB wetlands map. On each field site, GPS location, elevation, class identification, and ground photographs were recorded.

\subsection{Image processing}

Most of the image processing was performed in PCI Geomatica ${ }^{\circledR}$ (PCI Geomatics, 2018). The DEM tiles were first imported and checked for holes, where holes were filled using interpolated values and then mosaicked together using the PCI OrthoEngine ${ }^{\circledR}$ module of PCI Geomatica ${ }^{\circledR}$. The digital numbers of the Landsat5 TM images were first converted into top of atmosphere (TOA) reflectance values using the equations of Chander et al. (2009). Such a conversion also removes some of the atmospheric interference.

The Radarsat-2 dual-polarized (HH/HV) images were filtered for removing speckle, using a Gaussian filter developed by Eric Grunsky (Geological Survey of Canada, Ottawa), as in LaRocque et al. (2012). Speckle can be considered as noise, and its intensity must be attenuated to enhance fine details on SAR images (Goodman, 1976). Each image was then orthorectified with the "Radarsat-2 Rational Function Model" in the PCI OrthoEngine ${ }^{\circledR}$ module of PCI Geomatica ${ }^{\circledR}$ using the DEM and ground control points (GCP's). Between 100 and 200 GCP's (depending on the image) were extracted from orthorectified Landsat-5 TM data (NAD83 - UTM, zone 19, row T) for geo-correction. On average, the orthorectification process achieved a root mean square error (RMSE) of less than 1 pixel in the $\mathrm{x}$-direction and less than 1 pixel in the y-direction.

All the Alos-1 PalSAR images were imported, calibrated and orthorectified using the ASF MapReady ${ }^{\circledR}$ software (Alaska Satellite Facility Engineering Group, 2013). Each orthorectified image was then imported into PCI Geomatica ${ }^{\circledR}$ and filtered for speckle reduction, using a Gaussian filter, as for the Radarsat-2 images. The filtered and orthorectified Alos-1 PalSAR images were then mosaicked together using the "Automatic Mosaicking" processing in PCI Geomatica OrthoEngine ${ }^{\circledR}$ that requires the use of the DEM. Radiometric differences between adjacent images were minimized using a tonal-balancing histogram-matching method that compares the histogram of the image to be inserted in the mosaic with the mosaic histogram for each polarization.

Finally, all the datasets (Landsat-5 TM, Alos-1 PalSAR, Radarsat-2, and DEM) were re-projected to the New Brunswick Double Stereographic NAD83 (CanNBnad83) datum. All the input data were converted to the pixel spacing of $30 \mathrm{~m}$ of the Landsat5-TM imagery, allowing a direct superposition of all layers.

\subsection{Image classification}

Representative training areas of each of the sixteen land cover classes, based on 340 training sites (Table 2), were delineated over the orthorectified Landsat-5 TM. Training areas included at least ten sites per class for adequate class representation and were delineated within relatively large features, having exactly 10 pixels each in size. The training areas were randomly drawn throughout the study area, but the number of training areas by class reflected the relative frequency of the different land cover classes in the study area.

A non-parametric decision tree type classifier, Random Forests (RF), was applied to various combinations of DEM, Landsat-5 TM images, HH and HV polarization SAR images either from Alos-1-PalSAR L-band and/or Radarsat-2 C-band. RF does not assume a normal distribution of the input data (Breiman, 2001), The algorithm used in this study is an adaptation of the code of Horning (2010) by the first author. We used as settings a forest of 500 independent decision trees with the default value for the mtry variable, which is the number of variables randomly sampled as candidates at each node split. The default value includes all input features, i.e., all pixels are randomly sampled as candidates at each node split. RF randomly selects two third of the training data (that are referred as "In Bag" data) to develop one decision tree. This tree is then validated using the remaining third of the training data referred to as "Out of Bag data". The process is repeated for the 500 individual decision trees and produces 500 independent classifications. These independent classifications are then combined into the final classification (Waske, Braun 2009). When there are relatively limited training data for some classes, RF allows bootstrap aggregating of the "In Bag" data to increase the number of training pixels. RF is not sensitive to noise or over-classifying. RF gives an estimate of the importance of each input image for the classification (Pal, 2005; Gislason et al., 2006; Waske, Braun, 2009) under the form of a "Mean Decrease Accuracy" plot. The higher the image is on the "Mean Decrease Accuracy" plot Y-axis, the more useful the image was in the classification (Strobl et al., 2008; Louppe et al., 2013).

\subsection{Accuracy assessment}

Classification accuracy was assessed first by comparing training areas with the equivalent classified land use in the imagery. Such comparison was performed under the form of a "confusion" or "error matrix", where each cell expresses the number of pixels classified with the class defined by the training areas. The confusion matrix also allows computing the overall accuracy and the Kappa coefficient. The overall accuracy is the average of individual User's class accuracy, i.e., the probability that a pixel in the classified image belongs to the right class, weighted by the size of the class in the classified or reference image (Congalton, 1991). Finally, the Kappa coefficient of Cohen (1968) is defined as a weighted measure of agreement between the number of wellclassified pixels, while a value close to $0 \%$ corresponds to poor 
classification accuracy and a value closer to $100 \%$ indicates a good classification accuracy.

The image classification accuracy only assesses the classified image accuracy, which is different than the field accuracy. A more robust accuracy assessment is to compare the resulting classified image with an independent set of field validation sites that have a GPS location. If the image returns the same class as the one observed at the validation sites, then the classified image is considered as correct, and the pixel related to this validation site is associated with a value of 1 ; otherwise, its value will be zero. A percentage of correct identification was then computed as a function of the total number of validation sites. Such a comparison was not made using a classical confusion matrix because we only use the validation sites for the wetland classes, and some misidentifications are due to confusion with nonwetland classes.

\section{RESULTS}

\subsection{Effect of wetland water level on the images}

The effect of the different water levels (high-water and low-water levels) in the wetlands is visible in the true-colour composite of the Landsat-5 TM images (Figure 2), as well as in the false-colour composites of the Radarsat-2 (Figure 3 ) and of the Alos-PalSAR images (Figure 4).

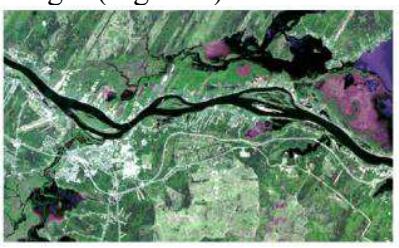

(a) May 2011 (High-water level)

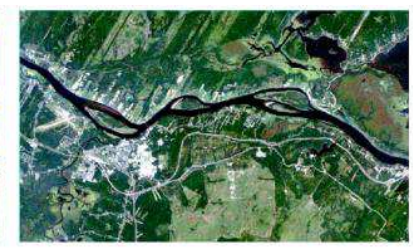

(b) September 2010 (Low-water level)
Figure 2. True-colour composite of the Landsat-5 TM image acquired (a) during a high-water level, and (b) during a low-water level. Each composite is made as follows: TM3 in red, TM2 in green, and TM1 in blue.

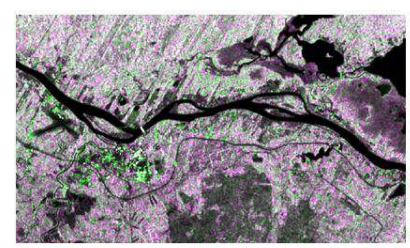

(a) June 2010 (High-water level)

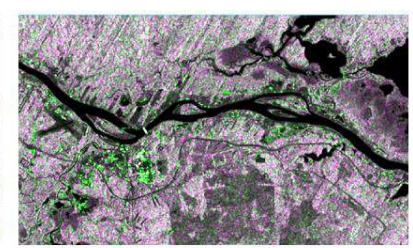

(b) September 2010 (Low-water level)
Figure 3. False-colour composite of the Radarsat-2 dualpolarized C-HH and C-HV images acquired (a) during a high-water level, and (b) during a low-water level. Each composite is made as follows: $\mathrm{HH}$ in red, $\mathrm{HV}$ in green, and $\mathrm{HH}$ in blue.

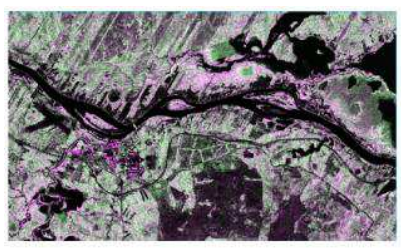

(a) May 2010 (High-water level)

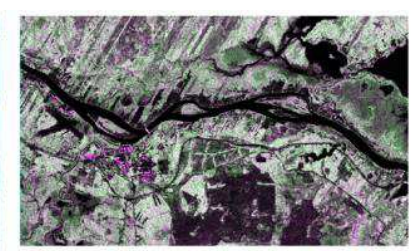

(b) August 2010 (Low-water level)
Figure 4. False-colour composite of Alos-1 PalSAR L-HH and L-HV mosaics acquired (a) during a high-water level, and (b) during a low-water level. Each composite is made as follows: $\mathrm{HH}$ in red, $\mathrm{HV}$ in green, and $\mathrm{HH}$ in blue.
Also, during the flood event, forested wetlands appear distinctively bright (light green) on both SAR images (Figure 5), as the interaction between the water and the trees produce a double-bounce scattering resulting to a bright return. In the case of the Landsat5-TM, no usable image acquired during a flood event was available because of the presence of an intermediate to high cloud cover during this event.

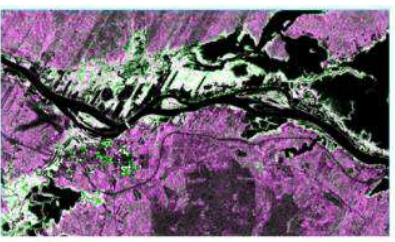

(a) Radarsat-2 (C-HH and C-HV)

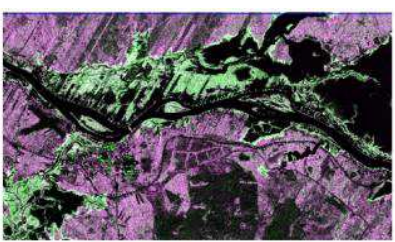

(b) Alos-1 PalSAR (L-HH and L-H)
Figure 5. False-colour composite of the SAR images acquired during a flood event (a) Radarsat-2 dual-polarized C$\mathrm{HH}$ and $\mathrm{C}-\mathrm{HV}$ image, and (b) Alos-1 PalSAR dualpolarized $\mathrm{L}-\mathrm{HH}$ and $\mathrm{L}-\mathrm{HV}$ image. Each composite is made as follows: $\mathrm{HH}$ in red, $\mathrm{HV}$ in green, and $\mathrm{HH}$ in blue.

\subsection{Image classification}

The overall accuracy and the Kappa coefficient are compared for the various image combinations of optical and both SAR images (Table 3). This table shows that, whatever the combination, the image classification accuracies are very often better when the images acquired during a flooding event are added to the image combination. The highest classification overall accuracy is achieved by using either the Landsat-5 TM and DEM data (94.9\%) or when both Radarsat-2 and/or Alos-1 PalSAR dualpolarized SAR images are added to the classification (94.3\%).

\begin{tabular}{|c|c|c|c|c|c|}
\hline \multirow[b]{2}{*}{ Data combination ${ }^{1}$} & \multicolumn{3}{|c|}{ Water level } & \multirow{2}{*}{ 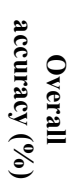 } & \multirow{2}{*}{ 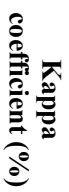 } \\
\hline & 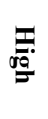 & 5 & 武 & & \\
\hline TM + DEM & $\mathrm{X}$ & $\mathrm{X}$ & & 94.9 & 94.6 \\
\hline $\mathrm{TM}+\mathrm{AP} 1$ & $\mathrm{X}$ & $\mathrm{X}$ & & 86.3 & 85.2 \\
\hline $\mathrm{TM}+\mathrm{AP} 1$ & $\mathrm{X}$ & $\mathrm{X}$ & $\mathrm{X}$ & 87.5 & 86.6 \\
\hline $\mathrm{TM}+\mathrm{RS} 2$ & $\mathrm{X}$ & $\mathrm{X}$ & & 88.2 & 87.4 \\
\hline $\mathrm{TM}+\mathrm{RS} 2$ & $\mathrm{X}$ & $\mathrm{X}$ & $\mathrm{X}$ & 90.6 & 89.9 \\
\hline $\mathrm{TM}+\mathrm{AP} 1+\mathrm{DEM}$ & $\mathrm{X}$ & $\mathrm{X}$ & & 91.1 & 90.5 \\
\hline $\mathrm{TM}+\mathrm{AP} 1+\mathrm{DEM}$ & $\mathrm{X}$ & $\mathrm{X}$ & $\mathrm{X}$ & 91.0 & 90.3 \\
\hline $\mathrm{TM}+\mathrm{RS} 2+\mathrm{DEM}$ & $\mathrm{X}$ & $\mathrm{X}$ & & 92.8 & 92.3 \\
\hline $\mathrm{TM}+\mathrm{RS} 2+\mathrm{DEM}$ & $\mathrm{X}$ & $\mathrm{X}$ & $\mathrm{X}$ & 93.7 & 93.2 \\
\hline $\mathrm{TM}+\mathrm{RS} 2+\mathrm{AP} 1+\mathrm{DEM}$ & $\mathrm{X}$ & $\mathrm{X}$ & & 92.8 & 92.2 \\
\hline $\mathrm{TM}+\mathrm{RS} 2+\mathrm{AP} 1+\mathrm{DEM}$ & $\mathrm{X}$ & $\mathrm{X}$ & $\mathrm{X}$ & 94.3 & 93.9 \\
\hline
\end{tabular}

1 TM: Landsat-5 TM; RS2: Radarsat-2; AP1: Also-1 PalSAR; DEM: Digital Elevation Model.

Table 3. Classification accuracies (\%) as a function of the image combination

In RF, the importance of each input data in the classification using all the dataset is ranked on the "Mean Decrease Accuracy" plot (Figure 6). It shows that the DEM is the most important input data in the image classification. The middle infrared (TM5) and the near-infrared (TM4) bands of Landsat-5 TM come in second place, the optical images acquired during low-water-levels being more important than the ones taken during high-water levels. The Radarsat-2 C-band images are in the top ten of the most effective input datasets. The other optical Landsat-5 TM bands and the Alos-1 PalSAR L-band images have lower importance in the image classification. However, SAR images acquired during a 
flooding event are more important in the classification than the other SAR images.

The classified images produced with the data combination having the two best classification accuracies are presented in Figure 7 and Figure 8 . While both classifications have similar overall accuracies, using only the Landsat-5 TM and DEM data produces an image where there is an apparent large extent of the forested wetlands across the study area (Figure 7).

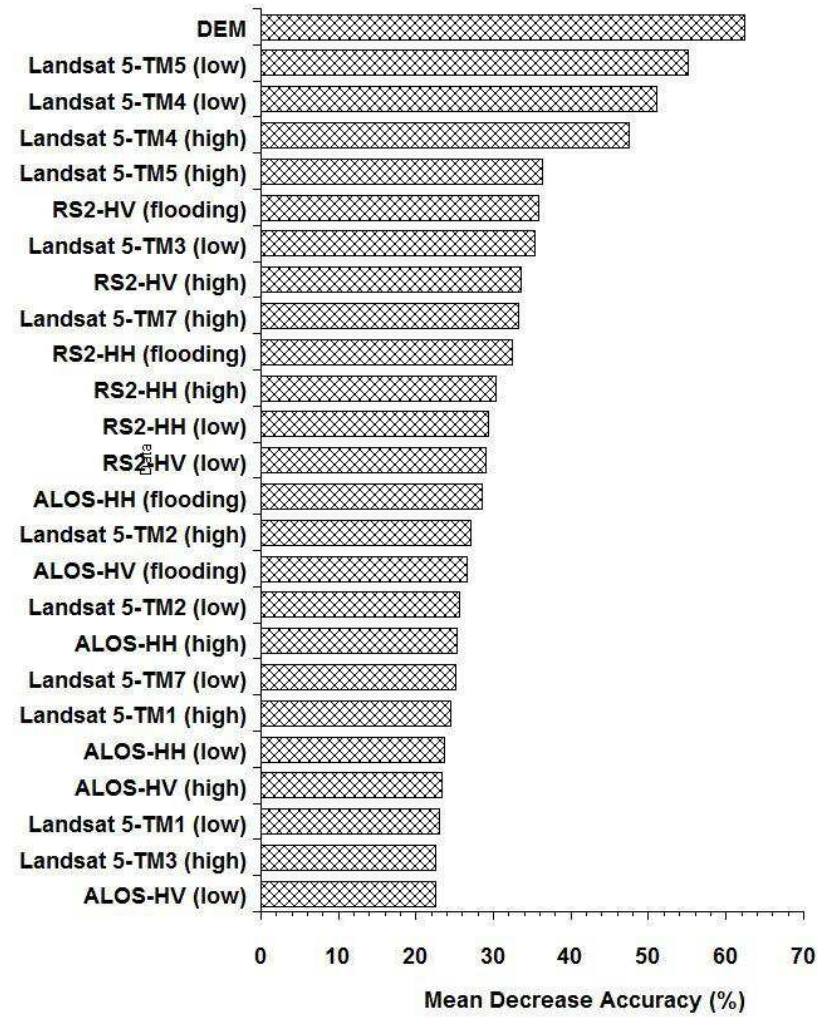

Figure 6. Variable importance produced by the Random Forests classifier applied to the full dataset of Landsat-5 TM, Alos-1 PalSAR, and Radarsat-2 images, and DEM.

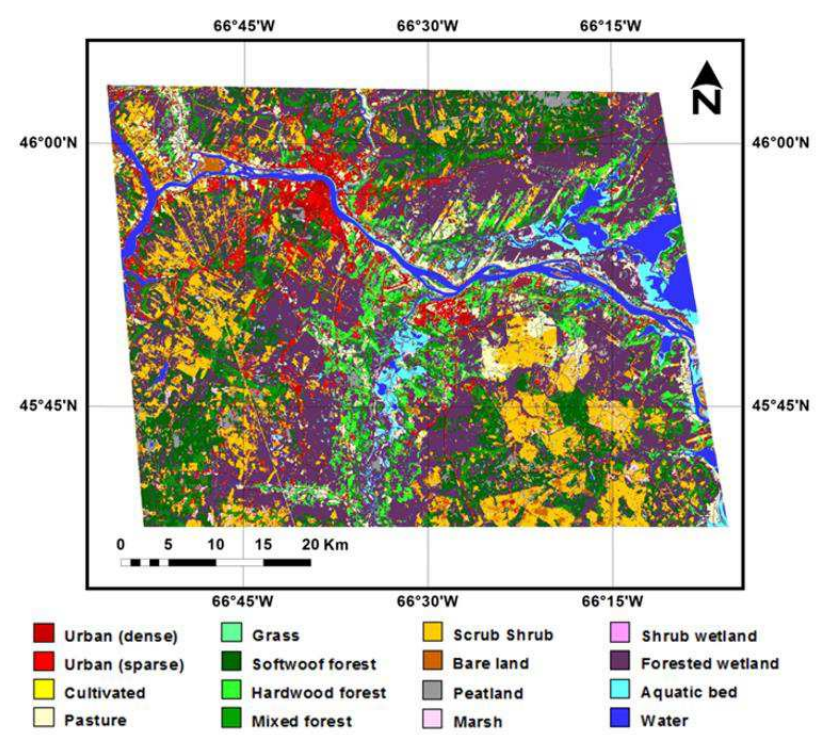

Figure 7. Classified image produced with the combination of Landsat-5 TM and DEM.

By contrast, the image produced with the addition of both SAR image types shows a less extent for the forested wetland (Figure
8). Therefore, the overall classification accuracy is not a good indicator of the accuracy, and it is the need to validate the classification using data acquired over GPS sites that were not used in the classification.

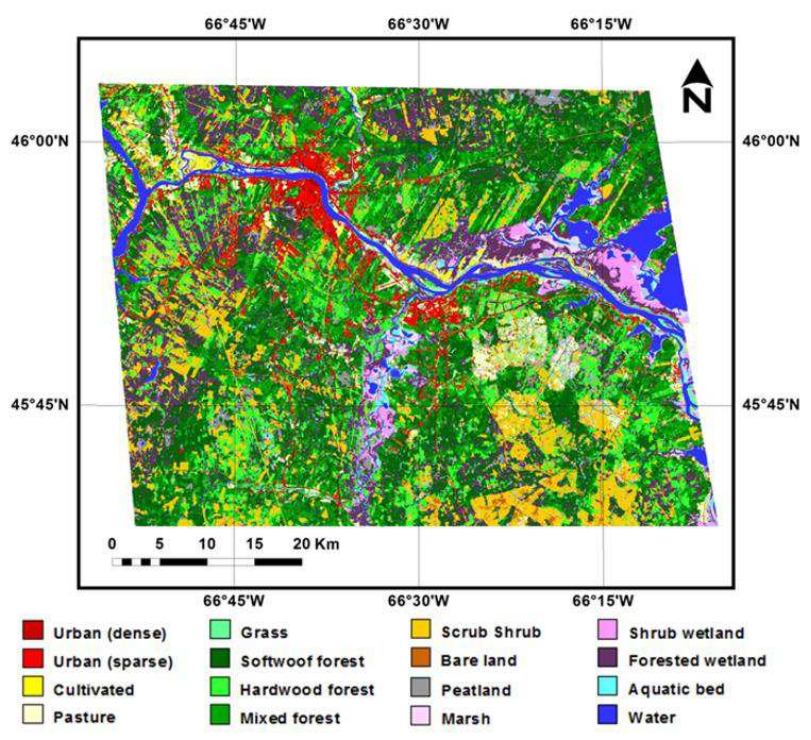

Figure 8. Classified image produced with the full combination of Landsat-5 TM, Alos-1 PalSAR, and Radarsat-2, and DEM.

\subsection{Validation accuracies}

Analyzing the performance of each image combination based solely on the image classification accuracies is not enough, and it is necessary to compare the classified images with independent validation data sets. This validation accuracy should come from the comparison between the classified image and independent sites identified on the base of field observations.

Out of the 199 wetland sites, only $74.1 \%$ were correctly identified from the Landsat-5 TM and the DEM classified image (Table 5). Adding SAR images in the classification, the number of correctly identified wetland validation sites is higher, particularly when the image acquired during a flooding event is also considered, the difference being higher when the Alos-1 PalSAR images are used alone or in combination with the Radarsat- 2 images. The number of correctly identified sites is the highest when all the dataset is used (195 sites or $97.9 \%)$. When only one type of SAR images is used, the number of correctly identified sites is higher with Alos1 PalSAR (180 sites or $90.5 \%$ ) than with the Radarsat-2 images (176 sites of $88.2 \%$ ). In all cases, these percentages of correctly identified wetland sites are well above the 89 correctly identified sites wetland sites (44.7\%) using the NB wetlands map coming from the two maps produced by the Province of New Brunswick.

\begin{tabular}{|l|c|c|c|c|c|}
\hline \multicolumn{1}{|c|}{ Input Data $^{1}$} & $\begin{array}{c}\text { With } \\
\text { flood } \\
\text { event }\end{array}$ & \multicolumn{2}{|c|}{$\begin{array}{c}\text { Correctly } \\
\text { identified }\end{array}$} & \multicolumn{2}{|c|}{$\begin{array}{c}\text { Poorly } \\
\text { identified }\end{array}$} \\
\hline & & $\mathrm{N}$ & $\%$ & $\mathrm{~N}$ & $\%$ \\
TM \& DEM & & 147 & 74.1 & 52 & 25.9 \\
TM + AP1 + DEM & & 170 & 85.3 & 29 & 14.7 \\
TM + AP1 + DEM & $\mathrm{X}$ & 180 & 90.5 & 19 & 9.5 \\
TM + RS2 + DEM & & 173 & 86.9 & 26 & 13.1 \\
TM + RS2 + DEM & $\mathrm{X}$ & 176 & 88.2 & 23 & 11.8 \\
TM + AP1 + RS2 + DEM & & 185 & 93.0 & 14 & 7.0 \\
TM + AP1 + RS2 + DEM & $\mathrm{X}$ & 195 & 97.9 & 4 & 2.1 \\
NB wetlands map & & 89 & 44.7 & 110 & 55.3 \\
\hline
\end{tabular}

1 TM: Landsat-5 TM; RS2: Radarsat-2; AP1: Also-1 PalSAR; DEM: Digital Elevation Model. 
Table 5. Overall statistics about the correct identification of the 199 wetland validation sites on the classified images, related with each image combination, or on the NB wetlands map

When either Radarsat-2 and/or Alos-1 PalSAR data are used in the image classification, most of the misidentifications are related to wetland sites not being classified in the correct wetland class, and very few are wetland sites being classified into a non-wetland class (Table 6).

\begin{tabular}{|c|c|c|c|c|c|c|}
\hline \multirow[t]{2}{*}{ Input Data ${ }^{1}$} & \multirow[t]{2}{*}{$\begin{array}{l}\text { With } \\
\text { flood } \\
\text { event }\end{array}$} & \multicolumn{2}{|c|}{$\begin{array}{c}\text { Non- } \\
\text { wetland } \\
\text { class }\end{array}$} & \multicolumn{2}{|c|}{$\begin{array}{c}\text { Wrong } \\
\text { wetland class }\end{array}$} & \multirow{2}{*}{$\begin{array}{c}\text { Total } \\
\mathrm{N}\end{array}$} \\
\hline & & $\mathrm{N}$ & $\%$ & $\mathrm{~N}$ & $\%$ & \\
\hline TM + DEM & & 12 & 5.8 & 40 & 20.1 & 52 \\
\hline $\begin{array}{l}\mathrm{TM}+\mathrm{AP} 1+ \\
\mathrm{DEM}\end{array}$ & & 8 & 4.1 & 20 & 10.3 & 29 \\
\hline $\begin{array}{l}\text { TM + AP1 + } \\
\text { DEM }\end{array}$ & $\mathrm{X}$ & 2 & 1.2 & 17 & 8.5 & 19 \\
\hline $\begin{array}{l}\mathrm{TM}+\mathrm{RS} 2+ \\
\mathrm{DEM}\end{array}$ & & 8 & 4.1 & 18 & 8.9 & 26 \\
\hline $\begin{array}{l}\mathrm{TM}+\mathrm{RS} 2+ \\
\mathrm{DEM}\end{array}$ & $\mathrm{X}$ & 7 & 3.8 & 16 & 8.0 & 23 \\
\hline $\begin{array}{l}\mathrm{TM}+\mathrm{AP} 1+ \\
\mathrm{RS} 2+\mathrm{DEM}\end{array}$ & & 9 & 4.7 & 4 & 2.1 & 14 \\
\hline $\begin{array}{l}\mathrm{TM}+\mathrm{AP} 1+ \\
\mathrm{RS} 2+\mathrm{DEM}\end{array}$ & $\mathrm{X}$ & 1 & 0.6 & 3 & 1.5 & 4 \\
\hline $\begin{array}{l}\text { NB wetlands } \\
\text { map }^{2}\end{array}$ & & 56 & 28,2 & 54 & 27,1 & 110 \\
\hline
\end{tabular}

1 TM: Landsat-5 TM; RS2: Radarsat-2; AP1: Also-1 PalSAR; DEM: Digital Elevation Model.

2 When observation sites do not belong to any class in the NB wetlands map, they are recorded as belonging to the "non-wetland" class

Table 6. Distribution of the poorly identified wetland validation sites as a function of the source of error

When all the dataset is used, only four sites are poorly identified. Three sites are not in the proper wetland class, and the last one is mapped as a non-wetland class. Their rather small width characterizes these four sites, close the spatial dimension of one pixel. For the NB wetlands map, about half of the 100 poorly identified sites are associated with wetland validation sites not being mapped as a wetland, the remaining half being sites that are not classified in the right wetland class.

\section{DISCUSSION}

In the present study, the RF classifier was applied to multitemporal SAR and optical images combined with DEM data. Our study also showed that combining optical, C-band and/ or L-band SAR, and DEM data strongly improved the wetland mapping accuracies, particularly when using validation sites. The benefit to use images from multi-sensors for wetland mapping was already shown by Li and Chen (2005), Bourgeau-Chavez et al. $(2009 ; 2015 ; 2016)$, Corcoran et al. (2012, 2013), LaRocque et al. (2014), Amani et al. (2018), Jahncke et al. (2018) and Mahdianpari et al. (2020). SAR and optical images are complementary. SAR has a unique ability to detect surface texture and provides information on scattering mechanisms that are related to surface roughness (and thus to the presence or absence of vegetation as well as to the vegetation type) and soil moisture content. Optical images, such as Landsat-5 TM, allow acquiring information on the reflective properties that are related to the presence or absence of vegetation, the vegetation type, and the surface moisture content if the canopy is sparse enough.
The variable importance plot (Figure 6) shows that the DEM is the most important input data in the classification. A similar result was obtained by Jahncke et al. (2018). It can be explained by the fact that wetlands are usually found in lowlands. The second and third most important input variables are the Landsat5 TM shortwave-infrared (TM5) and near-infrared (TM4) images. Harris et al. (2006) and Meingast et al. (2014) already showed that these bands are suitable for mapping wetlands, particularly those with low vegetation. However, both SAR images are less important in the classification than the Landsat-5 TM-4 and TM- 5 bands. Finally, the Alos- 1 PalSAR bands are less important in the classification than the Radarsat-2 images. The highest validation accuracy is achieved for all the wetland classes when both C-band and L-band images are used (Table 5). If only one of the two types of SAR images is used in the dataset, the number of well-identified GPS wetland validation sites is higher when the Alos-1 PalSAR L-band images are included in the image combination. Both SAR-type images used in the study have $\mathrm{HH}$ and HV polarizations. Figure 6 indicates that the crosspolarization (HV) is more important than the $\mathrm{HH}$ polarization for the Radarsat-2 C-band images, but not for the Alos-1 PalSAR Lband images. Therefore, the volume scattering, as measured by the HV polarization, seems to be more critical for the wetland mapping with the C-band. The highest penetration of the L-band Alos-1 PalSAR image induces a double-bounce scattering from the wetland areas that can be captured by the $\mathrm{HH}$ polarization. Such double-bounce scattering makes wetlands very distinct on the images (Figures $4 \mathrm{a}$ and $5 \mathrm{~b}$ ). L-HH images were already found to be suitable for mapping forested wetlands (Hess et al., 1990; Whitcomb et al., 2009) and peatlands (Yamagata, Yasuoka, 1993).

Our study used not only a multi-sensor approach but also a multitemporal data approach, as the satellite imagery was acquired during three different periods of water level inside wetlands (high-water level, low-water level and flooding) as well as in two different seasons (spring and summer). Combining multitemporal and multi-sensor approaches have already been shown to produce highly accurate wetland maps (Bourgeau-Chavez et al., 2009; 2015; Corcoran et al., 2013). Such an approach allows capturing seasonal differences in vegetation and water level conditions, helping for better discrimination between different wetland types. Figure 6 also shows that the Landsat TM images acquired during low-water levels are more important than the ones acquired during high-water levels. This is probably because the information input in the classification from the optical images is more related to the vegetation status than to the water level in the wetlands. Whatever the SAR sensor, the SAR images acquired during the flooding event are more important than those acquired at another time, indicating that the presence of water in the wetlands as observed on the SAR images is critical for the classification.

This study produced a classified image using multi-sensor and multi-temporal satellite images. By contrast to the NB wetlands map, all the classified images produced are in better agreement with the validation sites. The few misidentifications of the GPS wetland validation sites are mainly due to some wetland sites not being classified in the right wetland class, and there are very few confusions with the non-wetland classes. In the case of the NB wetlands map, there is a lot of misidentifications of the GPS wetland validation sites. These worst results are coming mostly from the interpretation of panchromatic air photos where wet areas are difficult to be detected. About half of the misidentifications are associated with sites mapped into a nonwetland class, the remaining half being sites not classified in the right wetland class. 


\section{CONCLUSION}

This study showed that using a dataset including Radarsat-2 (CHH, C-HV), Alos-PalSAR (L-HH, L-HV) and Landsat-5 TM images acquired during different water levels in the wetlands, and a DEM improves the mapping of wetland areas in the Greater Fredericton area. This good result is confirmed by the evaluation of the classified images produced with the validation sites. The few misidentifications of the GPS wetland validation sites are mainly due to wetlands not being classified in the right wetland class. There are very few confusions with non-wetland classes.

In this study, the selection of satellite images considers the hydrological conditions in the wetlands (high-water level, lowwater level, and flooding), and the leaf-on conditions. Corcoran et al. (2012) previously showed that leaf-on/leaf-off conditions could influence the mapping accuracy of wetlands. Further work is needed with images acquired on leaf-off conditions, but the good accuracies obtained in this study may indicate that there would be perhaps not the need to add such images.

This study was limited to SAR images acquired using large incident angles $\left(38^{\circ}\right.$ for the Alos-1 PalSAR and between $41^{\circ}$ and $46^{\circ}$ for the Radarsat-2 S6 images). Further work should be done by testing steeper incident angles since these angles allow better penetration of the wetland vegetation to detect flood conditions because of the shorter path-length, as already shown in Sokol et al. (2004). Also, using multi-beam mode images has been shown to provide better classification results than single beam modes (LaRocque et al., 2012; 2014). In this study, SAR images were also limited to two polarizations (HH and HV). Both Radarsat-2 and Alos-1 PalSAR polarimetric images are available that allow advanced polarimetric analysis, including target decomposition techniques, to better model the various scattering mechanisms. Several studies already showed that polarimetric variables could be helpful for wetland mapping (Touzi et al., 2007; Corcoran et al., 2013; Brisco et al., 2013).

The availability of the new Sentinel-1 C-band SAR satellite and the Sentinel-2 optical satellite should facilitate the mapping of land cover and wetlands, thanks to their better spatial resolution. Such data can be useful to produce a map for the wetland inventory for a large country like Canada, as suggested by Mahdianpari et al. (2020). Nevertheless, such mapping needs to consider also the non-wetland classes as well as wetlands can be different from one region to another, as well as the comparison between resulting the classified image with validation sites.

\section{ACKNOWLEDGEMENTS}

The study was funded by Environmental Trust Fund grant \#120143 awarded to Brigitte Leblon, Armand LaRocque, and Renata Woodward. The authors thank Duncan MacGillivray for data processing. Duncan MacGillivray's salary was covered by the YMCA Digital Skills program. Field data was collected with the help of Michael Mordini, Sophie Fialdès, Lara Kim, Todd Arseneault, and Damien LaRocque. Alos-1 PalSAR images were provided through the Alaska Satellite Facility from data grants awarded to Laura Bourgeau-Chavez. The Canadian Space Agency provided the Radarsat-2 images through a SOAR-CPT grant awarded to the Province of New Brunswick.

\section{REFERENCES}

Alaska Satellite Facility Engineering Group, 2013. ASF MapReady ${ }^{\circledR}$, Version 3.1.24. Fairbanks, AK, USA.
Amani, M., Salehi, B., Mahdavi, S. M., Granger, J., Brisco, B., Hanson, A., 2017. Wetland classification using multi-source and multi-temporal optical remote sensing data in Newfoundland and Labrador, Canada. Can J Remote Sens, 43(4), 360-373.

Amani, M., Salehi, B., Mahdavi, Sahel M., Brisco, B., Shehata, M., 2018. A multiple classifier system to improve mapping complex land covers: a case study of wetland classification using SAR data in Newfoundland, Canada. Int J Remote Sens, 39(21), 7370-7383.

Bourgeau-Chavez, L.L., Riordan, K., Powell, R.B., Miller, N., Barada, H., 2009. Improving wetland characterization with multi-sensor, multi-temporal SAR, and optical/infrared data fusion, 679-708. In Advances in Geoscience and Remote Sensing. InTech Publishers, New York.

Bourgeau-Chavez, L.L., Endres, S., Battaglia, M., Miller, M.E., Banda, E., Laubach, Z., Higman, P., Chaw-Fraser, P., Marcaccio, J., 2015. Development of a bi-national Great Lakes coastal wetland and land use map using three-season PalSAR and Landsat imagery. Remote Sensing, 7(7), 8655-8682.

Bourgeau-Chavez, L.L., Endres, S., Powell, R., Battaglia, M.J., Benscoter, B., Turetsky, M., Kasischke, E.S., Banda, E., 2016. Mapping boreal peatland ecosystem types from multitemporal radar and optical satellite imagery. Can J Forest Research, 47(4), 545-559.

Breiman, L., 2001. Random Forests. J Mach Learn, 45(1), 5-32.

Brisco, B., Kapfer, M., Hirose, T., Tedford, B., Liu, J., 2011. Evaluation of C-band polarization diversity and polarimetry for wetland mapping. Can J Remote Sens, 37(1), 82-92.

Brisco, B., Schmitt, A., Murnaghan, K., Kaya, S., Roth, A., 2013. SAR polarimetric change detection for flooded vegetation. Int $J$ Digit Earth, 6(2), 103-114.

Chander, G., Markham, B., Helder, D., 2009. Summary of current radiometric calibration coefficients for Landsat MSS, TM, ETM+, and EO-1 ALI sensors. Remote Sens Environ, 113(5), 893-903.

Cohen, J. 1968. Weighted Kappa: Nominal scale agreement with provision for scaled disagreement or partial credit. Psychol Bull, 70(4), 213-220.

Congalton, R.G., 1991. A review of assessing the accuracy of classifications of remotely sensed data. Remote Sens of Environ, $37(1), 35-46$

Corcoran, J.M., Knight, J.F., Brisco, B., Kaya, S., Cull, A., Murnagahn, K., 2012. The integration of optical, topographic, and radar data for wetland mapping in Northern Minnesota. Can J Remote Sens, 37(5), 564-582.

Corcoran, J.M., Knight, J.F., Gallant, A.L., 2013. Influence of multi-source and multi-temporal remotely sensed and ancillary data on the accuracy of Random Forest classification of wetlands in Northern Minnesota. Remote Sensing, 5(7), 3212-3238.

DNR (2006). New Brunswick wetland classification for 20032012 photo cycle. Government of New Brunswick, Department of Natural Resources, Fish and Wildlife Branch, Fredericton, NB, Canada. https://www2.gnb.ca/content/dam/gnb/Departments/nr$\mathrm{rn} / \mathrm{pdf} / \mathrm{en} /$ Publications/WETLANDS-Classificaton.pdf (29 Jan. 2020). 
Gislason, P.O., Benediktsson, J.A., Sveinsson, J.R. 2006. Random Forests for land cover classification. Pattern Recogn Lett 27(4), 294-300.

Goodman, J.W., 1976. Some fundamental properties of speckles. J Opt Soc Am, 66(11), 1145-1150.

Harris, A., Bryant, R.G., Baird, A.J., 2006. Mapping the effects of water stress on Sphagnum: preliminary observations using airborne remote sensing. Remote Sens Environ, 100(3), 363-378.

Henderson, F., Lewis, A., 2008. Radar detection of wetland ecosystems: a review. Int J Remote Sens, 29(20), 5809-5835.

Hess, L.L., Melack, J.M., Simonett, D.S., 1990. Radar detection of flooding beneath the forest canopy: a review. Int J Remote Sens, 11(7), 1313-1325.

Horning, N., 2010. Random Forests: an algorithm for image classification and generation of continuous field data sets. New York, American Museum of Natural History, Center for Biodiversity and Conservation. http://gisws.media.osakacu.ac.jp/gisideas10/viewpaper.php?id=342 (15 May 2019).

Jahncke, R., Leblon, B., Bush, P., LaRocque, A., 2018. Mapping wetlands in Nova Scotia with multi-beam Radarsat-2 Polarimetric SAR, optical satellite imagery, and Lidar data. Int $J$ Appl Earth Obs, 68, 139-156.

LaRocque, A., Leblon, B., Harris, J., Jefferson, C.W., Tschirhart, V., Shelat, Y., 2012. Surficial materials mapping in Nunavut, Canada, with multibeam RADARSAT-2 dual-polarization C-HH and C-HV, LANDSAT-7 ETM+, and DEM data. Can J Remote Sens, 38(3), 281-305.

LaRocque, A., Leblon, B., Woodward, R., Mordini, M., Bourgeau-Chavez, L., Landon, A., Camill, P., 2014. Use of Radarsat-2 and Alos-PalSAR SAR images for wetland mapping in New Brunswick. 2014 IEEE Geoscience and Remote Sensing Symposium (IGARSS 2014), Quebec City, QC, Canada, 2014, 1226-1229.

Li, J., Chen, W., 2005. A rule-based method for mapping Canada's wetlands using optical, radar and DEM data. Int $J$ Remote Sens, 26(22), 5051-5069.

Louppe, G., Wehenkel, L., Sutera, A., Geurts, P., 2013. Understanding variable importances in forests of randomized trees. Adv Neur In, 26, 431-439.

Mahdianpari, M, Salehi, B., Mohammadimanesh, F., Brisco, B., 2017. An assessment of simulated Compact Polarimetric SAR data for wetland classification using Random Forest algorithm. Can J Remote Sens, 43(5), 468-484.

Mahdianpari, M., Salehi, B., Mohammadimanesh, F., Brisco, B., Homayouni, S., Gill, E., DeLancey, E.R., Bourgeau-Chavez, L.L., 2020. Big Data for a big country: the first generation of Canadian wetland inventory map at a spatial resolution of $10-\mathrm{m}$ using Sentinel-1 and Sentinel-2 data on the Google Earth Engine cloud computing platform. Can J Remote Sens, https://www.tandfonline.com/doi/full/10.1080/07038992.2019.1 711366 (20 Jan. 2020).

Meingast, K.M., Falkowski, M.J., Kane, E.S, Potvin, L.R., Benscoter, B.W., Smith, A.M.S., Bourgeau-Chavez, L.L., Miller, M.E., 2014. Spectral detection of near-surface moisture content and water-table position in northern peatland ecosystems. Remote Sens Environ, 152, 536-546.

National Wetlands Working Group, 1997. The Canadian wetland classification system. Second ed. University of Waterloo and Environment Canada.

NOAA, 2017. Coast Change Analysis Program (C-CCAP): regional land cover scheme. National Oceanic and Atmospheric Administration, Office of Coastal Management, Charleston, NC, USA. https://coast.noaa.gov/data/digitalcoast/pdf/ccap-classscheme-regional.pdf (28 Jan. 2020).

Pal, M., 2005. Random Forest classifier for remote sensing classification. Int J Remote Sens, 26(1), 217-222.

PCI Geomatics, 2018. PCI Geomatica ${ }^{\circledR}$ Software, Version 2018, Markham, ON, Canada.

Reimer, K., 2009. The need for a Canadian wetland inventory. Conservator, 30(1), 36-45.

Sokol, J., McNairn, H., Pultz, T.J., 2004. Case studies demonstrating hydrological applications of C-band multipolarized and polarimetric SAR. Can J Remote Sens, 30(3), 470483.

Strobl, C., Boulesteix, A.L., Kneib, T., Augustin, T., Zeileis, A., 2008. Conditional variable importance for Random Forests. $B M C$ Bioinformatics, 9(1), 307.

Tiner, R.W., 1999. Wetlands indicators: a guide to wetland identification, delineation, classification, and mapping. Lewis Publishers, Boca Raton.

Touzi, R., Deschamps, A., Rother, G., 2007. Wetland characterization using polarimetric Radarsat-2 capability. Can J Remote Sens, 33, S56-S67.

Townsend, P.A. 2002. Relationships between forest structure and the detection of flood inundation in forested wetlands using $\mathrm{C}$ Band SAR. Int J Remote Sens, 23(3), 443-460.

Waske, B., Braun, M., 2009. Classifier ensembles for land cover mapping using multitemporal SAR imagery. ISPRS J Photogramm, 64 (5), 450-457.

Whitcomb, J., Moghaddam, M., McDonald, K., Kellndorfer, J., Podest, E., 2009. Mapping vegetated wetlands of Alaska Using L-band radar satellite imagery. Can J Remote Sens, 35(1), 54-72.

White, L., Brisco, B., Pregitzer, M., Tedford, B., Boychuk, L., 2014. Radarsat-2 beam mode selection for surface water and flood mapping. Can J Remote Sens, 40(2), 135-151.

Yamagata, Y., Yasuoka, Y., 1993. Classification of wetland vegetation by texture analysis methods using ERS-1 and JERS-1 images. 1993 IEEE International Geoscience and Remote Sensing Symposium (IGARSS 1993), Tokyo, Japan, 1614-1616. 